\title{
Competitive resource allocation to metabolic pathways contributes to overflow metabolisms and emergent properties in cross-feeding microbial consortia
}

\section{Authors: Ross P. Carlson, Ashley E. Beck, Poonam Phalak, Matthew W. Fields, Tomas Gedeon, Luke Hanley, William R. Harcombe, Michael A. Henson, \& Jeffrey J. Heys}

This is a postprint of an article that originally appeared in Biochemical Society Transactions on April 2018. DOI: 10.1042/BST20170242

Carlson RP, AE Beck, P Phalak, MW Fields, T Gedeon, L Hanley, WR Harcombe, MA Henson, JJ Heys, "Competitive resource allocation to metabolic pathways contributes to overflow metabolisms and emergent properties in cross-feeding microbial consortia," Biochemical Society Transactions, April 2018; 46(2):269-284. 


\section{Competitive resource allocation to metabolic pathways contributes to overflow metabolisms and emergent properties in cross-feeding microbial consortia}

Ross P. Carlson, Ashley E. Beck, Poonam Phalak, Matthew W. Fields, Tomas Gedeon, Luke Hanley, William R. Harcombe, Michael A. Henson, and Jeffrey J. Heys

Resource scarcity is a common stress in nature and has a major impact on microbial physiology. This review highlights microbial acclimations to resource scarcity, focusing on resource investment strategies for chemoheterotrophs from the molecular level to the pathway level. Competitive resource allocation strategies often lead to a phenotype known as overï $\neg$, ow metabolism; the resulting overï $\neg$,ow byproducts can stabilize cooperative interactions in microbial communities and can lead to crossfeeding consortia. These consortia can exhibit emergent properties such as enhanced resource usage and biomass productivity. The literature distilled here draws parallels between in silico and laboratory studies and ties them together with ecological theories to better understand microbial stress responses and mutualistic consortia functioning.

Resources and cellular function are inextricably linked Nutrient scarcity is a major selective pressure for most life including microorganisms. Natural selec-tion has resulted in microorganisms which utilize limiting resources in competitive manners. Microbial acclimation to nutrient scarcity is a fundamental biological process which influences mass and energy flows through a continuum of biological scales, including individual microbial cells, micro-bial consortia, and ecosystems [1-4].

Scarcity of resources, such as anabolic and catabolic nutrients, can influence the elemental and macromolecular composition of microorganisms [5-9]. Organisms grown in nitrogen- or phosphorous-limited environments contain relatively smaller amounts of the respective elements in their biomass due to shifts in macromolecular composition such as protein to RNA ratios $[5,6]$. Resource scarcity has influenced the evolution of macromolecular sequences including DNA, RNA, and protein [10,11]. For example, codon usage in the marine bacterium Pelagibacter is biased toward low nitrogen-containing nucleotides, likely because of evolution under extreme nitrogen scarcity [12]. Microbial proteins involved in the transport of carbon, nitrogen, or sulfur sources typically contain less of the respective element than an average protein, thereby reducing the quandary of investing a limiting resource into enzymes for its acquisition $[5,13,14]$. Competitive use of scarce resources extends to relatively minor cellular metabolite pools [15]. For example, production of the iron-containing cofactor ferredoxin is reduced when iron availability is scarce while production of the iron- 
free cofactor flavodoxin increases [16]. The competitive investment of scarce resources also influences the aggregate investment into both metabolite pools and enzymes used to drive cellular function; it has been proposed that the investment is minimized [17-19].

Resource scarcity influences regulation and function of metabolic networks. The typical bacterial proteome accounts for $50-70 \%$ of the total cellular mass with metabolic enzymes accounting for $15-20 \%$ of this macromolecular pool $[20,21]$. Natural selection has enriched populations for microorganisms that allocate scarce resources to functions that affect outcomes of competition. These include highly efficient mass and energy utilization strategies that are appropriate for nutritional availabilities [22-26]. Competitive cellular functions, such as the complete oxidation of a substrate using the TCA cycle as opposed to partial oxidation through glycolysis, require a larger resource investment into enzymes and metabolite pools. The availability of appropriate resources therefore constrains whether a certain cellular function can be realized. The tradeoff between resource availability and biological functioning has been conceptualized by ecologists using the 'Darwinian Demon' thought experiment [27]. A Darwinian Demon is a 'superspecies' that is unconstrained by resource limitations and can optimize all aspects of fitness simultaneously. If such an organism was feasible, it would outcompete all other organisms, leading to a monoculture. However, manifestation of the Darwinian Demon is precluded by the requirement that resources allocated to one function cannot typically be allocated elsewhere. This limits how many discrete processes can be optimized at a given time.

\section{Acclimation to nutrient scarcity can dramatically shift phenotype}

Acquisition of mass and energy from the environment is a prerequisite for life. Imbalances or perturbations in the acquisition of mass and energy are common occurrences due to feast and famine events associated, for example, with diel or seasonal cycles. Microorganisms have evolved competitive strategies to maximize fitness during these events including strategies that excrete large quantities of organic byproducts. These phenotypes are widely observed in prokaryotes and eukaryotes and have been called overflow metabolism, Crabtree effect, or Warburg effect dependent on observation in bacteria, fungi, or mammalian cells (reviews and further data can be found in refs $[23,24,28-32])$. A recent set of chemostat experiments examined acclimations of Escherichia coli cultures grown under three separate nutrient limitations: (1) glucose, the energy source, and an essential macronutrient, (2) ammonium, an essential macronutrient, and (3) iron, an essential micronutrient $[1,33]$. Each nutrient limitation was examined at four distinct levels of stress using chemostats operated at different dilution rates [34] (Figure 1). Chemostat nutrient stress is controlled via the bioreactor dilution rate, which is equal to the culture-specific growth rate, and is not determined via the concentration of the limiting substrate in the growth medium [34].

The E. coli cultures acclimated to increasing levels of nutrient scarcity by secreting increasingly larger fractions of catabolized glucose carbon as organic byproducts. Organic byproducts were observed even though the cultures were grown under oxic conditions, consistent with an overflow metabolism. The type and distribution of the organic byproducts changed as a function of nutrient limitation and the degree of nutrient scarcity (Figure 1). For example, iron-limited E. coli cultures grown at extreme nutrient scarcity secreted more than $70 \%$ of the catabolized glucose carbon as organic byproducts, primarily lactate; ammonium-limited E. coli chemostat cultures secreted $\sim 40 \%$ of the catabolized glucose carbon as organic byproducts, primarily acetate, whereas glucose-limited cultures secreted up to $4 \%$ of the glucose as organic byproducts, primarily formate [1].

The elemental composition of the culture biomass also varied with nutrient limitation and degree of stress, consistent with the tenets of ecological stoichiometry [6,35]. The different nutrient scarcities resulted in different biomass degrees of reduction (oxidizible electrons per carbon mole, also a metric for biomass energy density) as well as different ratios of $\mathrm{C}: \mathrm{N}[1]$.

Overflow metabolisms have also been observed at the high end of the specific growth rate spectrum [29,31,36]. The fast growing E. coli cultures experienced nutrient stress based on a combination of metabolite transport kinetics, growth rate-associated resource allocation to cellular machinery like ribosomes, and competing resource investment into fermentative or respiratory pathways; these mechanisms are in contrast with the absolute nutrient scarcity studied in chemostat cultures (Figure 1). However, the studies on both the high and the low end of the growth rate spectrum arrived at similar interpretations, namely that overflow metabolism represents a competitive investment strategy for select environments $[29,31,33,36]$. 


\section{Chemostat basics}

1. At steady state, the culture specific growth rate $(\mu)$ is equal to the bioreactor dilution rate $(D)$ which is controlled by medium flow rate $(F)$ and bioreactor volume $(V)$ :

$$
\mu=D=F / V
$$

2. Chemostat growth is limited by one substrate $(S)$. Substrate limitation stress is controlled by dilution rate and Monod kinetic constants $K_{s}$ and $\mu_{\text {max }}$, not the feed concentration of substrate:

$$
S=\frac{D \cdot K_{S}}{\mu_{\max }-D}
$$

3. Steady state concentration of the growth-limiting substrate is a nonlinear function of dilution rate. Substrate limitation stress is higher at low dilution rates.

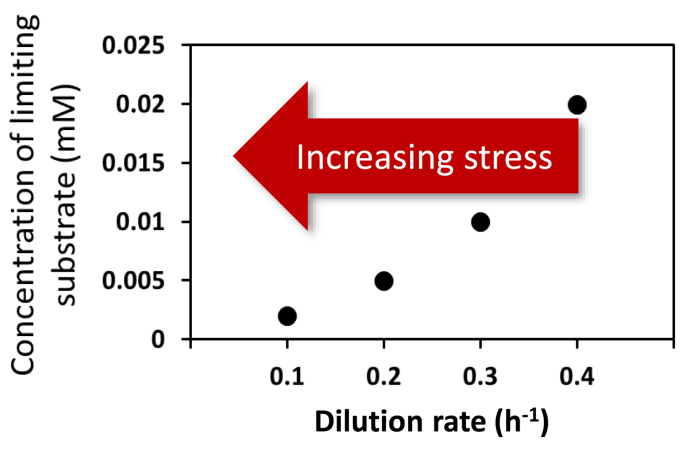

Nutrient-limited growth

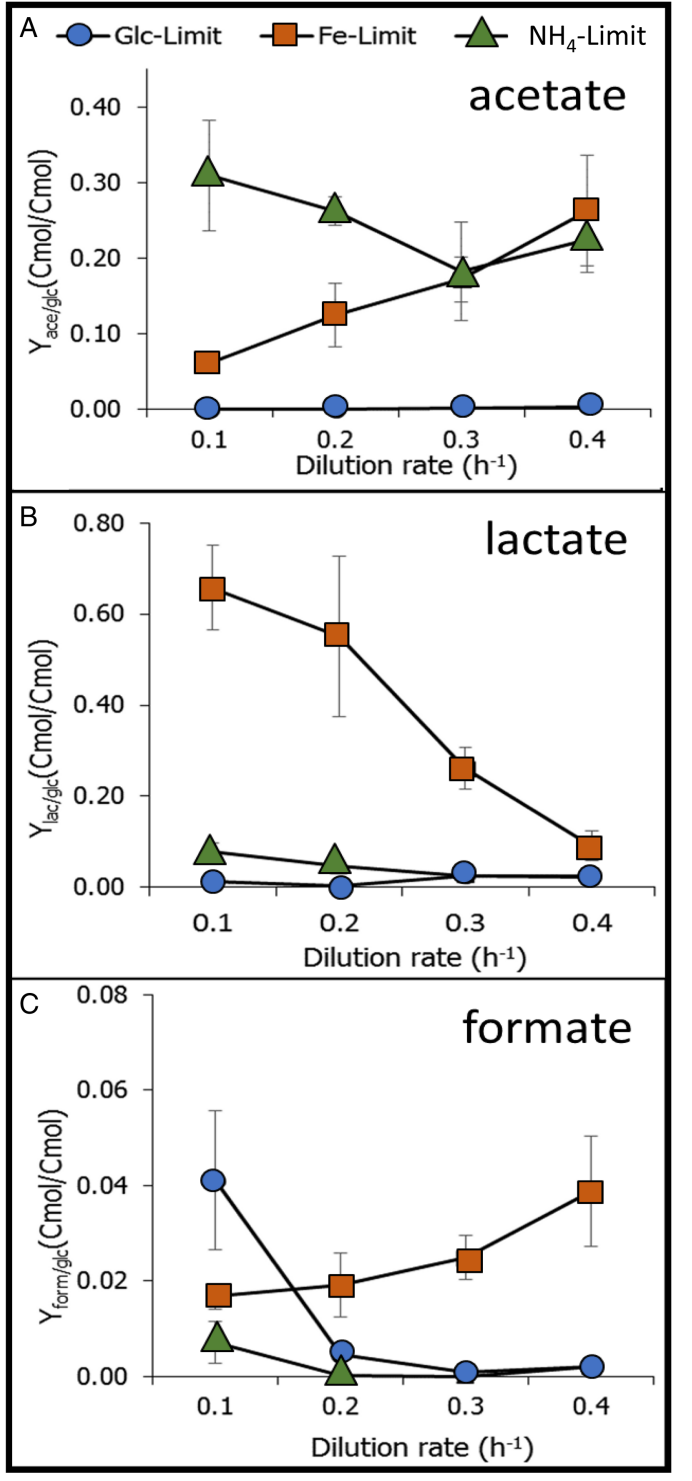

Figure 1. Chemostat operation theory and observation of overflow metabolism under multiple nutrient-limited conditions.

Left column: Basic chemostat theory regarding steady-state properties, including the control of nutrient-limited stress levels by controlling the bioreactor dilution rate. Right column: $E$. coli byproduct secretion profiles (A, acetate; B, lactate; C, formate) for three separate culturing limitations each examined at four separate levels of stress by setting four different dilution rates. All cultures were grown oxically. All three nutrient limitations resulted in an overflow metabolism where the cultures secreted substantial amounts of organic byproducts. Yields give the fraction of catabolized glucose carbon that is secreted as the organic byproduct. For instance, iron-limited cultures secreted up to $\sim 70 \%$ of the catabolized glucose carbon as lactate. Portions of the figure are modified from [1]. Cmol: carbon mole.

\section{In silico analysis can identify resource investment tradeoffs in metabolic pathways}

Metabolic networks, especially those observed in chemoheterotrophic generalists like E. coli, are capable of remarkable phenotypic plasticity enabled by robust biochemical networks [23,25,37-39]. Systems biology tools 
are needed to quantify the behavior of all but the simplest metabolic networks. Stoichiometric modeling approaches, including the related methods elementary flux mode analysis (EFMA) and flux balance analysis (FBA), can be used to predict and interpret tradeoffs in metabolic pathway investment strategies [40]. The two stoichiometric modeling approaches use the same formalism to create metabolic models using sets of mass balanced reactions and exploit similar or even identical properties of the metabolic models to predict and explain phenotype (Klamt et al. under review). Stoichiometric modeling approaches utilize data from omics datasets to build in silico representations of metabolism. These approaches utilize molecular-level data, but require minimal assumptions regarding enzyme kinetic parameters. This is a major strength because literature-reported kinetic parameters for the same enzyme can vary over orders of magnitude, complicating their inclusion into metabolic models and the interpretation of results [41-44].

Several stoichiometric modeling studies have examined resource investment into metabolic pathways using direct accounting of anabolic resources. Elementary flux modes (EFMs) are the simplest functioning metabolic protein investment schemes, making them ideal quanta for resource investment analyses [45]. Carlson [23,24] used EFMs and two different resource investment correlations to quantify relationships between resource investment into metabolic pathways and the efficiency of the pathways to convert substrate into biomass (Figure 2). The results were used to model fluxomics data collected from nutrient-limited E. coli cultures [24] and to interpret chemostat physiological data [1,33]. Another stoichiometric modeling approach developed in parallel used FBA to identify cellular phenotypes that maximized growth rate while constraining enzyme-occupied volume, based on sequence length as a proxy for molecular crowding [32]. These two resource investment analyses are conceptually and mathematically similar and are thought to identify similar metabolic phenotypes [46]. Additionally, cellular membrane space constraints have been used to explicitly account for resource investment constraints on phenotype [47]. Other stoichiometric modeling studies have investigated indirect proxies for resource investment into metabolic enzymes by, for instance, minimizing total phenotype flux or minimizing the number of utilized enzymatic steps [48-52].

The analysis of resource investment into metabolic pathways using stoichiometric modeling approaches has also expanded into larger scale cellular models that include not only the metabolism but also protein translation efficiency, cellular volume constraints, and macromolecular composition of the cell using resource balance analysis $[53,54]$. The more detailed analysis provides a multiscale basis for predicting and analyzing cellular resource investment scenarios, but also requires substantially more a priori data [55].

\section{Cost-benefit analysis of metabolic pathways predicts overflow metabolisms}

The optimal relationship between resource investment and the efficiency of an enzyme-catalyzed pathway can change with resource availability, resulting in optimality surfaces (Figure 2). These surfaces have been termed costbenefit curves, Pareto curves, efficiency frontier curves, or in some cases resource ratio curves $[17,56,57,91]$. The tradeoff curves can be viewed from the lens of the Darwinian Demon and the observation that allocation of resources to one function typically precludes their allocation to another; in other words, one function can only be increased by decreasing another. The analysis has analogs to industrial design strategies with the two extrema representing a high investment/low operating cost process and a low investment/high operating cost process (Figure 2) [23].

Many computational biology studies including kinetics-based studies $[25,28]$ predicted overflow metabolisms when resources required for enzyme assembly were constrained. These studies consistently noted that overflow metabolisms occur along optimal tradeoff surfaces and therefore do not reflect a wasteful metabolism as the overflow metabolism has sometimes been described. These studies also further highlight that overflow metabolism can be driven by optimization for either growth rate or growth yield.

The overflow metabolism associated with oxygen-limited growth is both well studied and widely acknowledged. Scarcity of a (catabolic) resource, such as a terminal electron acceptor (oxygen), limits the bioavailability of substrate energy, constraining metabolism to substrate-level phosphorylation with metabolic intermediates like pyruvate acting as electron acceptors for the production and secretion of organic acids [58-60]. The E. coli overflow metabolisms observed during carbon-, ammonium-, and iron-limited growth can be explained with a similar resource-based argument, though the mechanism is slightly different. The scarcity of a (anabolic) resource limits the bioavailability of substrate energy, constraining metabolism to substrate-level phosphorylation which extracts energy from a molecule with minimized investment into enzymes; the resulting metabolic intermediates, which require large resource investment to oxidize, are secreted. 


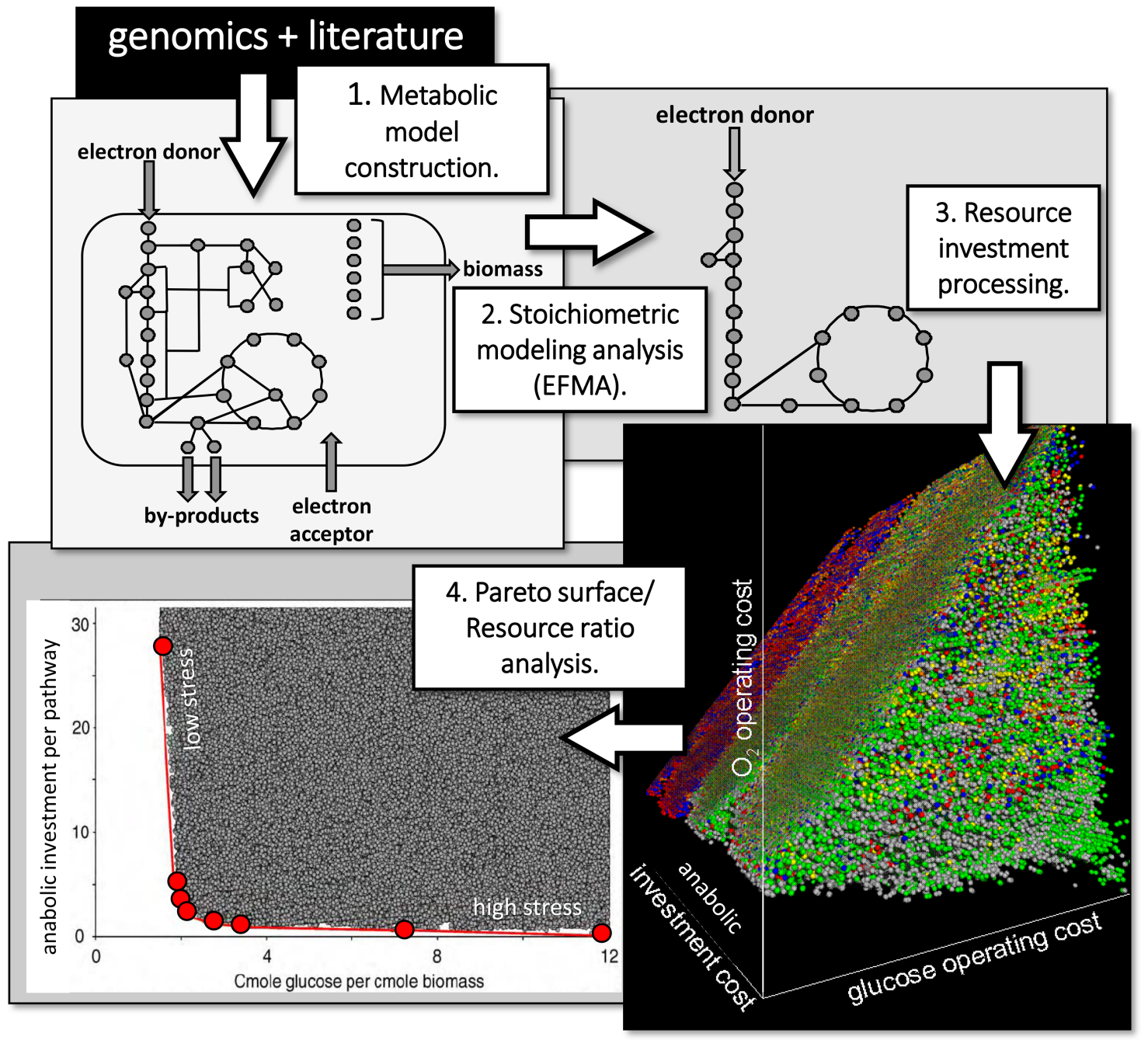

Figure 2. Process to perform resource allocation analysis of metabolic pathways.

(1) A stoichiometric representation of the metabolic system is created using genomics and literature. (2) The model is analyzed for mathematically defined biochemical pathways using EFMA. EFMs define the steady-state metabolic capabilities of the stoichiometric model. (3) Resource investment criteria and metabolic efficiency properties can be calculated for each distinct EFM. The co-ordinates for each point quantify the resource requirements to produce a carbon mole of biomass. Point color coding is based on different enzyme usage, and details can be found in $[4,23]$. The investment vs. function tradeoff curves can be visualized by plotting the EFM properties in 2-, 3-, or higher-dimensional spaces and identifying the Pareto surface of optimal functioning (minimal investment and function costs). Portions of the figure are modified from [23,71].

Overflow metabolisms are commonly observed phenomena [23,24,28-32]. A few key questions regarding overflow metabolism include (1) do all observations of overflow metabolisms reflect effective resource usage, (2) how do unstructured planktonic growth vs. structured biofilm environments alter which metabolic strategies are competitive, (3) what role does metabolite toxicity and environmental modification play in driving byproduct secretion, and (4) to what extent is the process of secreting partially oxidized byproducts simply symptomatic of laboratory conditions including media selection and therefore irrelevant to nature?

\section{Nutrient stress acclimation strategies can be quantified using opportunity costs}

Resource investment vs. function tradeoff curves provide detailed predictions of metabolic acclimations to gradients of resource scarcity [23]. Many of the predicted E. coli acclimations discussed above have been experimentally 
verified during steady-state growth in chemostats and are highlighted in this section. ATP opportunity costs, based on amino acid peptide-bond formation, have also been calculated as a quantitative reference. This opportunity cost is a conservative estimate, because many amino acids are also viable cellular energy sources [61].

1. Full TCA cycle vs. glyoxylate shunt (GS): The GS has historically been associated only with the catabolism of two-carbon organic compounds like acetate [62,63]. Contrary to this assertion, the GS has been observed during glucose-limited growth experiments $[1,33,63,64]$, as predicted from resource tradeoff analysis [23]. The GS uses two enzymes (isocitrate lyase and malate synthase) and bypasses three TCA cycle enzyme complexes (isocitrate dehydrogenase, $\alpha$-ketoglutarate dehydrogenase, and succinyl-CoA synthetase), saving an investment of $\sim 22000$ amino acids' worth of carbon, nitrogen, and sulfur as well as 66 000 ATP equivalents for peptide-bond formation.

2. Oxic use of pyruvate formate lyase (Pfl) vs. pyruvate dehydrogenase complex (PDHc): Pfl converts pyruvate into acetyl-CoA and formate, consists of two protein subunits, and requires a total of 1520 amino acids. In contrast, the pyruvate dehydrogenase complex converts pyruvate into acetyl-CoA, $\mathrm{NADH}$, and $\mathrm{CO}_{2}$, consists of 60 protein subunits, and requires 42096 amino acids to synthesize or $\sim 25$ times more anabolic resource and cellular volume than Pfl and $\sim 120000$ more ATP equivalents for peptide bonds. Historically, Pfl has been associated only with anoxic growth [65,66], but active Pfl has been reported during micro-aerophilic growth. In addition, formate secretion has been observed during both iron-limited and glucose-limited chemostat growth, and formate has been implicated in long-term aerobic glucose-limited E. coli acclimation studies $[33,58,67,68]$. These trends are consistent with in silico resource allocation predictions [23]. The oxygen-sensitive portion of Pfl can be replaced by the relatively small YfiD repair protein [69], potentially making it possible to maintain Pfl functionality by continuously replacing the oxygen-damaged protein. YfiD protein consists of 127 amino acids and can be synthesized de novo more than 300 times while still requiring fewer resources than a single functional PDHc.

3. Entner-Doudoroff (ED) vs. Embden-Meyerhof-Parnas (EMP) glycolysis pathway: The ED pathway has historically been associated only with pentose sugar catabolism [70]. The ED pathway requires $\sim 1500$ fewer amino acids to assemble relative to the classic EMP pathway although it also extracts one fewer ATP from substrate-level phosphorylation in the conversion of glucose to pyruvate [71]. Experimental evidence and genomic analyses strongly suggest that the ED pathway is utilized during nutrient scarcity for the catabolism of glucose, again consistent with in silico predictions [23,70,72].

4. Shifts in overflow metabolism byproducts as a function of nutrient scarcity: Tradeoff surface analysis predicts a series of byproducts that change with the degree of resource stress [23]. Consistent with predictions, E. coli cultures grown under moderate levels of nutrient scarcity stress secreted acetate and formate in the presence of oxygen. The formate and acetate secretion is predicted to decrease at extreme levels of nutrient stress with the metabolism shifting toward lactate secretion. These predictions in aggregate are consistent with E. coli chemostat studies $[1,29,33,64]$. An aerobic metabolism that completely oxidizes glucose to $\mathrm{CO}_{2}$ requires an investment of $\sim 50$ atoms of iron and produces $\sim 30$ ATP per glucose; the minimal iron investment ATP strategy is a homolactic acid synthesis pathway that does not require any iron investment and produces two ATP per catabolized glucose.

The discussed opportunity costs do not explicitly consider enzyme parameters. The relationship between pathway flux, proteome, enzyme kinetic parameters, and enzyme stability has been the subject of many studies and has implications for predictive resource allocation models [73-75]. Metabolic control analysis (MCA) provides theory for developing an initial basis for predicting pathway relationships. MCA has established that flux through most metabolic pathways is a systemic property that is not typically subject to individual enzyme kinetic parameters [76-78]. MCA and numerous experimental studies have demonstrated the shortcomings of the 'rate-limiting' enzyme concept; pathway flux is instead a complex function of metabolite concentrations, enzyme concentrations, and regulation [76,79]. This basic tenet of MCA has been supported through many elegant studies which have shown that flux through metabolic pathways does not show a strong correlation with enzyme levels. For instance, the experimental overexpression of individual glycolysis enzymes (up to $\sim 1400 \%$ increase) including the 'rate-limiting' enzyme had no substantial effect on overall pathway flux [79]. Instead, the pathways possessed mechanisms that allowed systemic shifts in metabolite levels and regulation to acclimate to the enzyme perturbations maintaining similar overall flux [73-76,79-81].

The resource opportunity costs discussed in this section are based on the powerful concept of an EFM. The core predictive capabilities of stoichiometric modeling approaches, including EFMA and FBA, are independent 
of kinetic parameters or absolute fluxes and instead identify ratios of reaction fluxes that meet user-defined criteria. The investment example in this section makes no assumptions about the absolute concentrations of enzymes in each EFM; only concentration ratios between participating enzymes are assumed. The minimum possible proteome associated with an EFM has a $1: 1$ ratio between every participating enzyme or enzyme complex. Attempting to scale individual enzyme concentrations based on in vitro measurements of enzyme parameters would neglect the effects of metabolite concentrations, regulation, and the findings from MCA which demonstrated that typically, there is no 'rate-limiting' enzyme. EFM enzyme concentrations could likely be perturbed randomly ( \pm order of magnitude) around the $1: 1$ ratio without substantial effects on overall pathway flux, based on experimental and theoretical studies $[73,79,80]$. Additionally, enzyme stability would not influence the predicted results because EFM and FBA both assume steady states. Protein stability would require additional ATP maintenance energy to degrade and reassemble enzymes, but the amino acids and cofactors would remain inside the system boundaries.

Modern systems biology has a general trajectory toward incorporating an ever-greater number of assump-tions based on experimental data such as transcript level or enzyme abundance to create ever more complex representations of metabolism. A few key questions in the field of metabolic modeling are (1) to what reso-lution and what metabolic cost has evolution selected cellular control of central metabolism, (2) what is the quantitative tradeoff between predictive capabilities of in silico models and the number of assumptions includ-ing flux, enzyme parameters, and omics data relationships, (3) what scientific questions benefit from adding more parameters or fewer parameters to a computational representation of biological processes, (4) what is the relationship between the number of assumed parameters/model complexity and the description of fundamental principles of biological organization, and finally (5) under what culturing conditions does predicted metabolic optimality exceed the resolution of natural selection?

\section{Overflow metabolism provides a mechanism for consortia cross-feeding}

Most naturally occurring microbes exist in multispecies communities where they co-operate or compete for resources. Cross-feeding is a common consortium interaction motif in which a microbe excretes a compound that is utilized by another individual [82]. Several synthetic consortia have been constructed to study these interactions. The systems can be categorized broadly based on anabolic excretions like amino acids [83-86], catabolic excretions like organic acids [87,88], and mixed systems that involve both amino acids and organic acids $[89,90]$.

The presented work focuses on catabolic exchanges based on the relationship to overflow metabolism.

Resource allocation tradeoffs can facilitate cross-feeding; stress acclimation of one trophic level can lead to over-

flow metabolisms, creating resource niches for organisms in a second trophic level [3]. By consuming the byproduct, the secondary consumer population uses resources that would otherwise be neglected while removing chemicals that could represent both a thermodynamic constraint and the inhibitory byproduct [91]. This positive feedback mechanism enables the consortia to more effectively deplete environmental resources, increase productivity, and can even allow metabolism of substrates that would not be feasible by a monoculture $[88,92]$.

Consortia with increased efficiency have evolved and been engineered in E. coli $[68,83,87,93]$. One example is an evolved cross-feeding $E$. coli consortium that is reproducibly selected during long-term, glucose-limited chemostat experiments. Over the span of $\sim 100$ generations, the monocultures spontaneously evolved into acetate cross-feeding consortia with $\sim 15 \%$ increase in biomass productivity and enhanced nutrient depletion properties when compared with the inoculum monoculture (reviewed in refs [68,93]). A synthetic consortium also demonstrated enhanced biomass productivity and resource depletion when two populations were engi-neered for division of labor; one population catabolized glucose and produced acetate and the second popula-tion consumed the acetate [87]. The engineered consortium showed $20 \%$ improvement in biomass productivity during chemostat cultivation and $50-100 \%$ improvement in biomass productivity during biofilm cultivation when compared with wild-type E. coli monocultures. In both consortium examples, the basic schema entailed one population using a substrate-level phosphorylation-focused metabolism with heavy reliance on glycolysis and the second population using an oxidative phosphorylation-focused metabolism with a heavy reliance on the TCA cycle. The 'metagenome' of the evolved and synthetic consortia contained the same metabolic poten-tial as wild-type E. coli; however, the enzymes either had different regulation patterns or were partitioned to different populations. 


\section{Division of labor permits reduced aggregate resource investment into enzymes and substrate improving consortia productivity}

The acetate cross-feeding consortia presented in the preceding section have higher glycolysis fluxes in one population and higher TCA fluxes in the other population when grown in chemostats [93]. This results in an additional benefit to division of labor and cross-feeding: a better functional return on resource investment into metabolism. Enzyme flux is driven by investment into both enzyme (E) and substrate (S) pools (Figure 3); substrate pools during steady-state growth represent a substantial resource investment. Free metabolite pools and enzymatic protein investment both account for $\sim 5 \%$ of $E$. coli dry mass [15,20]. An investment analysis to drive enzyme flux, quantified in terms of carbon moles (Cmoles), is shown in Figure 3. A target cellular function, quantified by an enzyme flux, can be achieved through a combination of investment into enzyme pools and substrate pools. The minimum aggregate enzyme and substrate carbon investment are highlighted in Figure 3. Relatively small fluxes are achieved with minimal aggregate investment using a 'push' metabolism where more resource is invested into the substrate pool than the enzyme pool (region labeled in Figure 3, top right panel). High fluxes are achieved with minimum aggregate investment through a 'pull' strategy where more resource is invested into the enzyme pool than the substrate pool. Increasing flux through a reaction does not require a linear increase in resource investment (Figure 3); instead, higher fluxes are relatively less resource intensive $[17-19,94,95]$.

Analysis of Figure 3 provides an interesting side story to examine recent reports that cellular metabolism can shift fluxes substantially while enzyme levels remain relatively unchanged [73-75]. Collectively, these data suggest that the cells are utilizing a flexible base metabolic proteome and a push mechanism, along with regulation, to drive function. This self-correcting organization would permit shifts in pathway fluxes via relatively inexpensive and fast shifts in metabolite pool and regulation as opposed to large restructuring of resources invested into the proteome $[73,80]$.

The resource savings from operating enzymes at higher fluxes as highlighted in Figure 3 may improve the fitness of cross-feeding populations compared with monocultures [39,83]. This concept is illustrated on a hypothetical chemoheterotrophic example in Figure 3 (lower panel); it is assumed that the enzymes can be described by Michaelis-Menten-type kinetics. Here, a wild-type population comprised of two cells is the reference case; this population completely oxidizes glucose, and each cell has a relative overall flux of 1 (arbitrary units of flux, e.g. mole/cell/h) and a relative resource investment requirement of 1 (arbitrary units of investment, e.g. Cmoles per cell). Therefore, total system flux and investment are each 2 (arbitrary units). Realistic quantitative fluxes and investment values are dependent on enzyme parameters; here, they are simplified for the sake of argument. The wild-type population is compared with a second population of two cells that specializes in glycolysis and therefore accumulates inhibitory organic byproducts. The cells have higher-relative glycolysis fluxes ( 2 arbitrary units each) consistent with an overflow metabolism. The cells only use approximately half the central metabolism enzymes when compared with the wild-type cells and operate a high glycolysis flux which reduces the overall investment (1.85 arbitrary units total system). The accumulated organic byproduct inhibits the cells, preventing the investment savings from leading to higher productivity. A third system is a cross-feeding consortium with one cell specializing in glycolysis and a second cell specializing in the TCA cycle. The flux per cell would be increased ( 2 arbitrary units) with this configuration; the two-fold higher fluxes require less than a two-fold increase in resource investment to achieve (1.85 arbitrary units total system) (Figure 3$)$. The reduced resource requirement is available for enhanced growth, providing an explanation for the enhanced biomass productivity seen in the naturally evolved and synthetically constructed consortia described in the previous section. These same arguments for functional return on investment are also likely relevant, to a degree, with the other mentioned synthetic consortia $[83-86,89,90]$.

A few key questions regarding cross-feeding interactions include (1) what number of metabolite exchanges can optimize overall system productivity, (2) how does the number of exchanges correlate to properties of enzyme-catalyzed steps like resource investment and energy-producing steps as theoretically explored in [96], and (3) how do these predictions in time-invariant, unstructured environments like a steady-state chemostat compare to temporally dynamic structured environments like biofilms? 

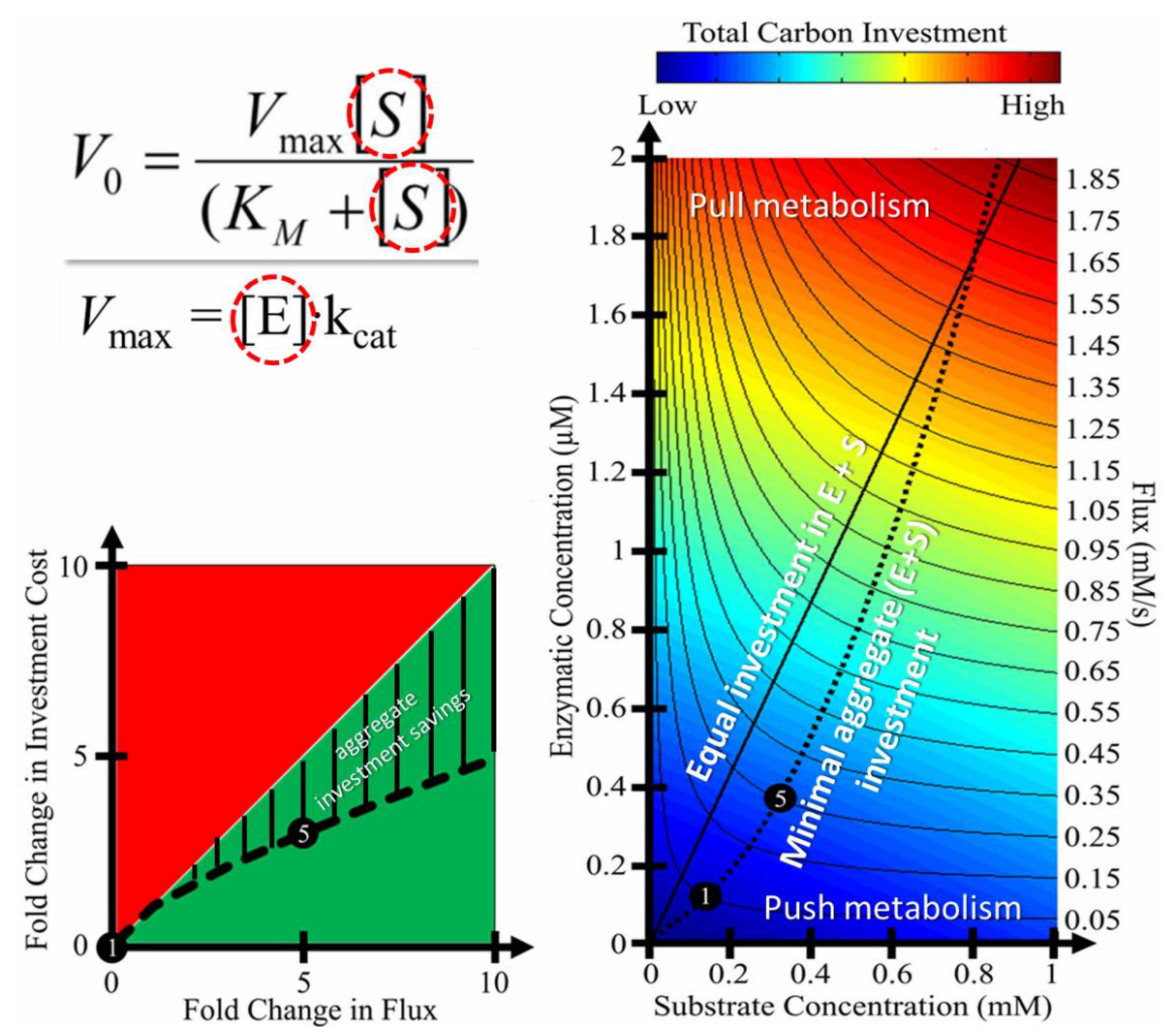

Substrate Concentration $(\mathrm{mM})$

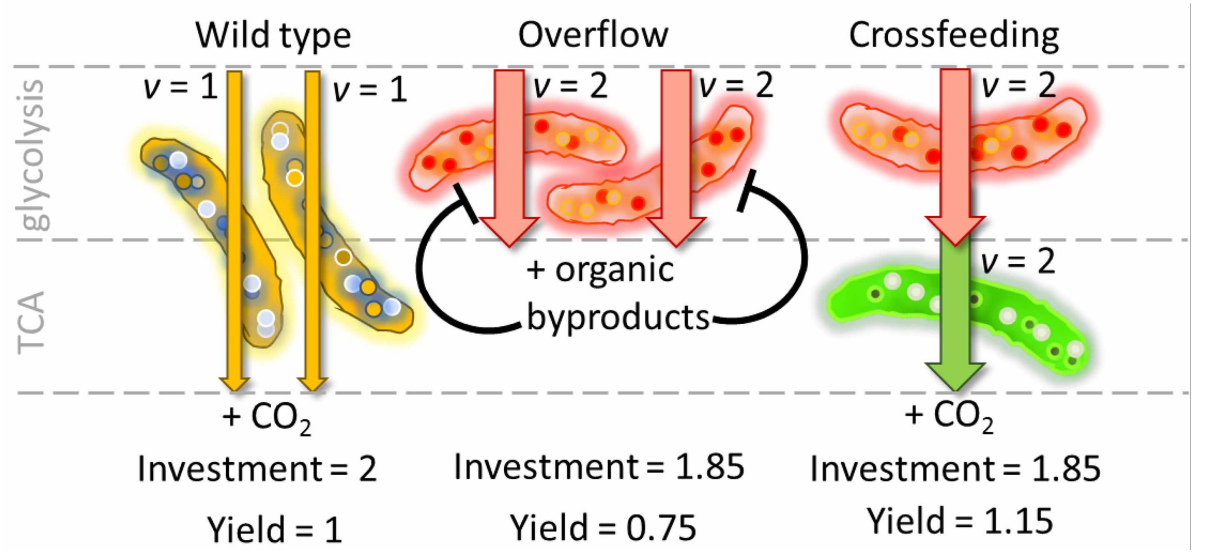

Figure 3. Optimal investment into enzyme and substrate pools leads to resource savings at high fluxes and contributes to consortia benefits.

Top panel: Analysis of driving reaction flux through investing resources (carbon moles) in different combinations of enzyme and substrate. Analysis assumed classic Michaelis-Menten-type kinetics where flux (enzyme velocity $V$ ) is driven by combinations of substrate pool concentration (S) and enzyme concentration (E). A target flux can be achieved through an optimal investment into enzyme and substrate pools, which is highlighted by the dotted line. The solid line indicates a scenario in which equal numbers of carbon moles are invested into enzyme and substrate pools. When the minimal aggregate investment strategy is below the equal investment curve, a push metabolism is most competitive where more carbon is invested into substrate pools than enzyme pools. Conversely, the optimal resource investment scenario when the minimal aggregate investment curve is above the equal investment line is a pull metabolism where more carbon is invested into enzyme pools than substrate pools. Enzyme and substrate parameters are obtained from the $E$. coli fumarase enzyme. Higher-relative fluxes do not require linear increases in resource investment. For example, increasing flux five-fold through the example system only requires approximately three-fold increase in carbon mole investment to achieve. Lower panel: Three different configurations of resource investment into cellular populations with different overall yields based on cross-feeding. See the main text for details. Portions of the figure are modified from [17]. 

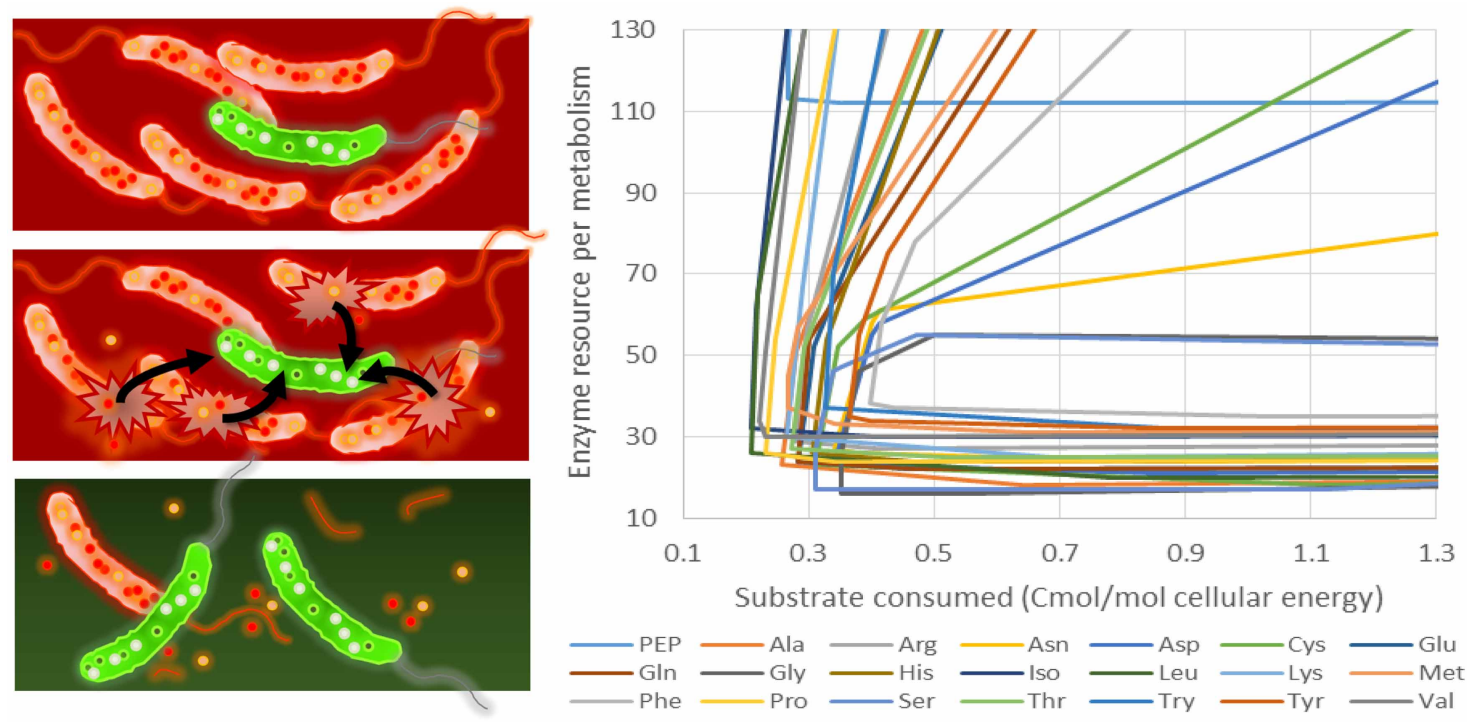

Figure 4. Extreme metabolite exchange in food webs: mass and energy flow via biomass turnover.

Left panel: Mass and energy transfer in many naturally occurring food webs includes primary producer biomass turnover which is consumed by heterotrophic levels. Primary producer biomass can be driven by mechanisms such as viral lysis and senescence. An in silico study by Hunt et al. 2016 examined the limitations on mass and energy transfer between trophic levels in a microbial food web. Separate analyses were considered, including complete consumption of primary producer biomass in entirety, as well as exclusive consumption of select biomass fractions such as individual amino acids. Right panel: Illustration of a tradeoff (Pareto) surface quantifying the cellular volume required to assemble a catabolic pathway for extracting ATP from an amino acid. All 20 amino acids were analyzed; a higher-resolution version can be found in ref. [61]. Portions of the figure are modified from [61].

\section{Biomass turnover as a mechanism of consortia mass and energy fluxes}

Synthetic and artificial consortia have become popular loci of research with many studies examining cellular interactions based on excreted metabolites like organic acids, amino acids, or quorum sensing molecules $[82,87,89,90]$. An extreme case of metabolite exchange, that sets an upper limit, is the total transfer of cellular biomass from one population to another via the utilization of lysed cell material. This is a common, naturally occurring food web interaction and provides a contrast with overflow metabolism-based interactions [2]. Ecosystem primary producers fix mass and energy, and the resulting biomass eventually serves as mass and energy sources for other trophic levels. The turnover of primary producer biomass occurs based on many mechanisms including predation, viral lysis, or senescence. Hunt et al. [61] have quantified the limits of mass and energy transfer from a primary producer trophic level to a secondary heterotrophic consumer level using both EFMA and FBA stoichiometric modeling approaches (Figure 4). The analysis considered a range of mass and energy exchanges including the selective catabolism of individual monomer pools, catabolism of entire macromolecular pools, and the catabolism of the aggregate primary producer biomass. The different potential substrate pools have different relative values as precursors for biomass or cellular energy production based on metabolite properties, including the degree of reduction and the entry point of metabolite(s) into the biochemical network. The bioavailability of mass and energy was also dependent on environmental conditions. Under oxygen sufficient conditions, $\sim 2.3$ autotroph cells are required to produce one heterotroph cell; the relationship changes to $\sim 4$ autotroph cells per heterotroph cell for oxygen scarce environments. This mechanism places major constraints on abundance relationships of primary producers and consumers and therefore has a very strong influence on the allocation of a limiting resource like nitrogen or oxygen.

\section{Diffusion limitation can alter resource allocation in biofilm consortia}

Most naturally occurring microorganisms grow as biofilms, attached to surfaces and often surrounded by extracellular polymers [97]. Spatially structured environments such as biofilms often constrain growth due to rate 

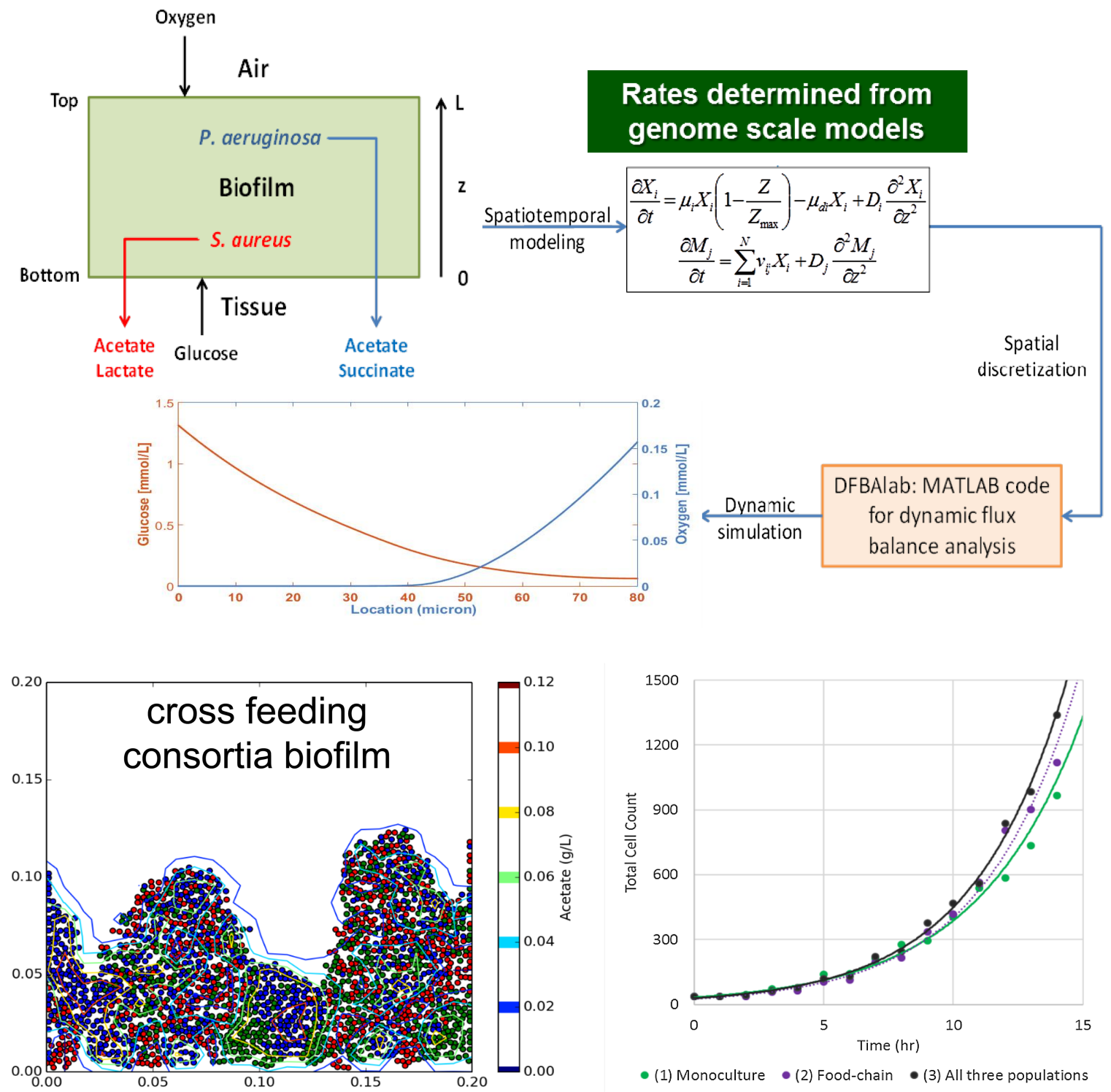

Figure 5. In silico analysis of biofilm consortia interactions including spatially resolved examination of metabolite inhibition.

Top panel: Overview of methodology for dynamic, spatially resolved analysis of biofilm consortia with two bacterial species and illustrated boundary conditions. The biofilm is discretized into nodes, and a linear programing problem is solved for each node to predict cell phenotype based on the local conditions. Cell substrate consumption and product secretion rates are then used to update extracellular mass balances at each node. Figure modified from [102]. Lower panel: Agent-based analysis of consortia biofilm explicitly accounting for organic acid cross-feeding and byproduct inhibition kinetics. The most diverse community had the highest biomass productivity based on its ability to effectively exploit more niches. All substrates entered the control volume from the top. Average, aggregate biomass productivity of the different configurations is shown on the right. Portions of the figure are modified from [109].

imbalances between diffusion and enzyme-catalyzed reactions [98]. The imbalances create concentration gradients leading to spatial chemical heterogeneity and spatially dependent phenotypes including overflow metabolisms [98]. Nutrient gradients generated by microbial growth influence the strength of competition [99] and the feasibility of mutualism [90]. These gradients, in turn, tend to drive segregation of competing genotypes, and mixing of cooperators [100], ultimately determining the composition and function of many microbial systems [101]. 
Stoichiometric modeling provides insights into the spatial distribution of metabolic strategies, and how nutrient gradients drive dynamics in the composition and function of microbial systems [89,98]. For example, a model identified how metabolic strategies of $E$. coli are segregated by the oxygen and carbon gradients that arise inside a colony [101]. Models can also illuminate dynamics in multispecies systems [82,102104]. Phalak et al. [105] investigated the stratification of Staphylococcus aureus and Pseudomonas aeruginosa in chronic wounds (Figure 5). Stoichiometric models suggest that this pattern is generated by differential growth, chemotaxis, and gradients in both oxygen and inhibitors. Modeling feedback between metabolic strategies and nutrient gradients has also been used to explain the productivity of fuel cells [103], the stable coexistence of bacteria in the human gut even when the species have very different growth rates [104], and even evolutionary dynamics in multispecies systems [100]. In all cases, it is clear that the optimal metabolic strategy for a cell changes through space and time, and there is dynamic feedback between metabolism and nutrient gradients.

Discrete agent-based (also called individual-based) modeling has also been developed to expand from population-averaged results to investigations of localized environments within biofilms and interactions between microbes [107]. Agent-based modeling allows attribution of different physiological and metabolic properties to distinct microbes in the model, properties which are often responsive to the varying local environments within biofilms, and gives the ability to describe adaptive behavior [107]. For example, agent-based models have been used to predict enhanced productivity of a biofilm community when inhibitory byproducts are consumed by a scavenger population [109] (Figure 5). Other models have predicted the optimal relationship between cell clustering and the transport rate of exchanged molecules [110]. These models provide a counter perspective to the continuous modeling methodologies applied with the FBA-based approaches. Methods are also being developed to integrate stoichiometric and individual-based modeling techniques and have been used to study diversification of metabolic phenotypes in P. aeruginosa biofilms as well as human microbiome consortia [111].

A few key questions associated with reaction-diffusion-controlled microorganism growth include (1) whether it is possible to control these systems by applying theory informed, resource gradients at the appropriate system boundaries or using technologies such as three-dimensional printing of microorganisms in hydrogels or droplet-based microfluidics to construct spatial structures that possess desirable functions, (2) to what extent can metabolic interactions be inferred from snap-shot measurements of spatial biomass distributions, and (3) at what size scale do the interactions need to be modeled to provide accurate representation of system physiology?

\section{Conclusion}

Resource scarcity shapes biological systems at every level, from individual microorganisms to microbial consortia to entire ecosystems. Resource investment can be analyzed at various levels, from elemental and macromolecular composition to metabolic pathway utilization to partitioning between enzymes and substrates. Strategic investment of scarce resources is predicted to be necessary for fitness and is supported by experimental observations. Continuously advancing techniques for the investigation of cost-benefit tradeoffs (e.g. stoichiometric and individual-based modeling methods), combined with ecological concepts, are yielding more insights into microbial metabolisms and interactions.

The study of microbial acclimations and adaptations to resource scarcity will lead to improved understanding of emergent properties in consortia and will enable improved engineering and control of industrial, environmental, and medical consortia. Computational modeling and analysis tools that predict the impact of resource scarcity in homogeneous planktonic cultures and diffusion-limited biofilm consortia are now available. These tools enable the rational engineering of microbial species and their cross-feeding interactions using synthetic biology to drive resource investment toward desirable outcomes such as enhanced synthesis of valuable metabolites, better microbiome function, or in the case of unwanted populations, the collapse of consortia responsible for medical infections.

\section{Abbreviations}

Cmoles, carbon moles; ED, Entner-Doudoroff; EFMA, elementary flux mode analysis; EFMs, elementary flux modes; EMP, Embden-Meyerhof-Parnas; FBA, flux balance analysis; GS, glyoxylate shunt; MCA, metabolic control analysis; PDHc, pyruvate dehydrogenase complex; Pfl, pyruvate formate lyase. 


\section{Funding}

This work was supported by National Science Foundation [Awards DMS-1361240, CBET-4171195], National Institutes of Health [Award U01EB019416], and Department of Defense Army Research Office ARO [Award W911NF-16-1-0463].

\section{Acknowledgements}

The authors like to acknowledge Kristopher Hunt and Hans Bernstein for their assistance with figure graphics.

\section{Competing Interests}

The Authors declare that there are no competing interests associated with the manuscript.

\section{References}

1 Folsom, J.P. and Carlson, R.P. (2015) Physiological, biomass elemental composition and proteomic analyses of Escherichia coli ammonium-limited chemostat growth, and comparison with iron- and glucose-limited chemostat growth. Microbiology 161, 1659-1670 https://doi.org/10.1099/mic.0. 000118

2 Schimel, J., Balser, T.C. and Wallenstein, M. (2007) Microbial stress-response physiology and its implications for ecosystem function. Ecology 88, 1386-1394 https://doi.org/10.1890/06-0219

3 Beck, A., Bernstein, H. and Carlson, R. (2017) Stoichiometric network analysis of cyanobacterial acclimation to photosynthesis-associated stresses identifies heterotrophic niches. Processes 5, 32 https://doi.org/10.3390/pr5020032

4 Lindemann, S.R., Bernstein, H.C., Song, H.-S., Fredrickson, J.K., Fields, M.W., Shou, W. et al. (2016) Engineering microbial consortia for controllable outputs. ISME J. 10, 2077-2084 https://doi.org/10.1038/ismej.2016.26

5 Elser, J.J., Acquisti, C. and Kumar, S. (2011) Stoichiogenomics: the evolutionary ecology of macromolecular elemental composition. Trends Ecol. Evol. 26, 38-44 https://doi.org/10.1016/j.tree.2010.10.006

6 Sterner, R.W. and Elser, J.J. (2002) Ecological Stoichiometry: The Biology of Elements From Molecules to the Biosphere. Princeton University Press, Princeton, NJ, p. 441

7 Dekel, E. and Alon, U. (2005) Optimality and evolutionary tuning of the expression level of a protein. Nature 436, 588-592 https://doi.org/10.1038/ nature03842

8 Makino, W., Cotner, J.B., Sterner, R.W. and Elser, J.J. (2003) Are bacteria more like plants or animals? Growth rate and resource dependence of bacterial C:N:P stoichiometry. Funct. Ecol. 17, 121-130 https://doi.org/10.1046/j.1365-2435.2003.00712.x

9 Zinn, M., Witholt, B. and Egli, T. (2004) Dual nutrient limited growth: models, experimental observations, and applications. J. Biotechnol. 113, 263-279 https://doi.org/10.1016/j.jbiotec.2004.03.030

10 Bragg, J.G. and Hyder, C.L. (2004) Nitrogen versus carbon use in prokaryotic genomes and proteomes. Proc. R. Soc. Lond. Ser. B 271, S374-S3S7 https://doi.org/10.1098/rsbl.2004.0193

11 Bragg, J.G. and Wagner, A. (2009) Protein material costs: single atoms can make an evolutionary difference. Trends Genet. 25, 5-8 https://doi.org/10. 1016/j.tig.2008.10.007

12 Giovannoni, S.J., Tripp, H.J., Givan, S., Podar, M., Vergin, K.L., Baptista, D. et al. (2005) Genome streamlining in a cosmopolitan oceanic bacterium. Science 309, 1242-1245 https://doi.org/10.1126/science.1114057

13 Baudouin-Cornu, P., Surdin-Kerjan, Y., Marlière, P. and Thomas, D. (2001) Molecular evolution of protein atomic composition. Science 293, 297-300 https://doi.org/10.1126/science.1061052

14 Bragg, J.G., Quigg, A., Raven, J.A. and Wagner, A. (2012) Protein elemental sparing and codon usage bias are correlated among bacteria. Mol. Ecol. 21, 2480-2487 https://doi.org/10.1111/j.1365-294X.2012.05529.x

15 Neidhardt, F.C., Ingraham, J.L. and Schaechter, M. (1990) Physiology of the Bacterial Cell: A Molecular Approach, Sinauer Associates: Sunderland, MA.

16 Erdner, D.L. and Anderson, D.M. (1999) Ferredoxin and flavodoxin as biochemical indicators of iron limitation during open-ocean iron enrichment. Limnol. Oceanogr. 44, 1609-1615 https://doi.org/10.4319/lo.1999.44.7.1609

17 Beck, A., Hunt, K., Bernstein, H.C. and Carlson, R. (2016) Interpreting and Designing Microbial Communities for Bioprocess Applications, From Components to Interactions to Emergent Properties: CE Eckert and CT Trinh. Elsevier, Amsterdam, Netherlands. Pacific Northwest National Laboratory (PNNL), Richland, WA, U.S.A.; Medium: X p

18 Carlson, R.P., Oshota, O.J. and Taffs, R.L. (2012) Systems analysis of microbial adaptations to simultaneous stresses. In Reprogramming Microbial Metabolic Pathways (Wang, X., Chen, J., Quinn, P., eds), pp. 139-157. Springer Netherlands, Dordrecht

19 Dourado, H., Maurino, V.G. and Lercher, M.J. (2017) Enzymes and substrates are balanced at minimal combined mass concentration in vivo. bioRxiv https://doi.org/10.1101/128009

20 Li, G.-W., Burkhardt, D., Gross, C. and Weissman, J.S. (2014) Quantifying absolute protein synthesis rates reveals principles underlying allocation of cellular resources. Cell 157, 624-635 https://doi.org/10.1016/j.cell.2014.02.033

21 Liebermeister, W., Noor, E., Flamholz, A., Davidi, D., Bernhardt, J. and Milo, R. (2014) Visual account of protein investment in cellular functions. Proc. Natl Acad. Sci. U.S.A. 111, 8488-8493 https://doi.org/10.1073/pnas.1314810111

22 Dhurjati, P., Ramkrishna, D., Flickinger, M.C. and Tsao, G.T. (1985) A cybernetic view of microbial growth: modeling of cells as optimal strategists. Biotechnol. Bioeng. 27, 1-9 https://doi.org/10.1002/bit.260270102

23 Carlson, R.P. (2007) Metabolic systems cost-benefit analysis for interpreting network structure and regulation. Bioinformatics 23, 1258-1264 https://doi.org/10.1093/bioinformatics/btm082

24 Carlson, R.P. (2009) Decomposition of complex microbial behaviors into resource-based stress responses. Bioinformatics 25, 90-97 https://doi.org/10. 1093/bioinformatics/btn589 
25 Molenaar, D., van Berlo, R., de Ridder, D. and Teusink, B. (2009) Shifts in growth strategies reflect tradeoffs in cellular economics. Mol. Syst. Biol. 5, $323 \mathrm{https}: / /$ doi.org/10.1038/msb.2009.82

26 Wessely, F., Bartl, M., Guthke, R., Li, P., Schuster, S. and Kaleta, C. (2011) Optimal regulatory strategies for metabolic pathways in Escherichia coli depending on protein costs. Mol. Syst. Biol. 7, 515 https://doi.org/10.1038/msb.2011.46

27 Law, R. (1979) Optimal life histories under age-specific predation. Am. Nat. 114, 399-417 https://doi.org/10.1086/283488

28 Schuster, S., Boley, D., Moller, P., Stark, H. and Kaleta, C. (2015) Mathematical models for explaining the Warburg effect: a review focussed on ATP and biomass production. Biochem. Soc. Trans. 43, 1187-1194 https://doi.org/10.1042/BST20150153

29 Basan, M., Hui, S., Okano, H., Zhang, Z., Shen, Y., Williamson, J.R. et al. (2015) Overflow metabolism in Escherichia coli results from efficient proteome allocation. Nature 528, 99-104 https://doi.org/10.1038/nature15765

30 Goel, A., Wortel, M.T., Molenaar, D. and Teusink, B. (2012) Metabolic shifts: a fitness perspective for microbial cell factories. Biotechnol. Lett. 34, 2147-2160 https://doi.org/10.1007/s10529-012-1038-9

31 Peebo, K., Valgepea, K., Maser, A., Nahku, R., Adamberg, K. and Vilu, R. (2015) Proteome reallocation in Escherichia coli with increasing specific growth rate. Mol. Biosyst. 11, 1184-1193 https://doi.org/10.1039/C4MB00721B

32 Beg, Q.K., Vazquez, A., Ernst, J., de Menezes, M.A., Bar-Joseph, Z., Barabasi, A.-L. et al. (2007) Intracellular crowding defines the mode and sequence of substrate uptake by Escherichia coli and constrains its metabolic activity. Proc. Natl Acad. Sci. U.S.A. 104, 12663-12668 https://doi.org/10.1073/ pnas.0609845104

33 Folsom, J.P., Parker, A.E. and Carlson, R.P. (2014) Physiological and proteomic analysis of Escherichia coli iron-limited chemostat growth. J. Bacteriol. 196, 2748-2761 https://doi.org/10.1128/JB.01606-14

34 Bull, A.T. (2010) The renaissance of continuous culture in the post-genomics age. J. Ind. Microbiol. Biotechnol. 37, 993-1021 https://doi.org/10.1007/ s10295-010-0816-4

35 Turner, C.B., Wade, B.D., Meyer, J.R., Sommerfeld, B.A. and Lenski, R.E. (2017) Evolution of organismal stoichiometry in a long-term experiment with Escherichia coli. R. Soc. Open Sci. 4, 170497 https://doi.org/10.1098/rsos.170497

36 Scott, M., Gunderson, C.W., Mateescu, E.M., Zhang, Z. and Hwa, T. (2010) Interdependence of cell growth and gene expression: origins and consequences. Science 330, 1099-1102 https://doi.org/10.1126/science.1192588

37 Kooijman, S.A.L.M. (2000) Dynamic Energy and Mass Budgets in Biological Systems, 2nd edn. Cambridge University Press, New York, NY

38 Papp, B., Teusink, B. and Notebaart, R.A. (2009) A critical view of metabolic network adaptations. HFSP J. 3, 24-35 https://doi.org/10.2976/1. 3020599

39 Pfeiffer, T., Schuster, S. and Bonhoeffer, S. (2001) Cooperation and competition in the evolution of ATP-producing pathways. Science 292, 504-507 https://doi.org/10.1126/science.1058079

40 Trinh, C.T., Wlaschin, A. and Srienc, F. (2009) Elementary mode analysis: a useful metabolic pathway analysis tool for characterizing cellular metabolism. Appl. Microbiol. Biotechnol. 81, 813-826 https://doi.org/10.1007/s00253-008-1770-1

41 Schomburg, I., Chang, A., Ebeling, C., Gremse, M., Heldt, C., Huhn, G. et al. (2004) BRENDA, the enzyme database: updates and major new developments. Nucleic Acids Res. 32, D431-D433 https://doi.org/10.1093/nar/gkh081

42 Chang, A., Scheer, M., Grote, A., Schomburg, I. and Schomburg, D. (2008) BRENDA, AMENDA and FRENDA the enzyme information system: new content and tools in 2009. Nucleic Acids Res. 37, D588-D592 https://doi.org/10.1093/nar/gkn820

43 Teusink, B., Passarge, J., Reijenga, C.A., Esgalhado, E., van der Weijden, C.C., Schepper, M. et al. (2000) Can yeast glycolysis be understood in terms of in vitro kinetics of the constituent enzymes? Testing biochemistry. Eur. J. Biochem. 267, 5313-5329 https://doi.org/10.1046/j.1432-1327.2000. 01527.x

44 Leaf, T.A. and Srienc, F. (1998) Metabolic modeling of polyhydroxybutyrate biosynthesis. Biotechnol. Bioeng. 57, 557-570 https://doi.org/10.1002/(SICl) 1097-0290(19980305)57:5<557::AID-BIT8>3.0.C0;2-F

45 de Groot, D.H., Planqué, R., van Boxtel, C., Bruggeman, F.J. and Teusink, B. (2017) https://doi.org/10.1101/16717

46 Vazquez, A., Beg, Q.K., de Menezes, M.A., Ernst, J., Bar-Joseph, Z., Barabási, A.-L. et al. (2008) Impact of the solvent capacity constraint on E. coll metabolism. BMC Syst. Biol. 2, 7 https://doi.org/10.1186/1752-0509-2-7

47 Zhuang, K., Vemuri, G.N. and Mahadevan, R. (2011) Economics of membrane occupancy and respiro-fermentation. Mol. Syst. Biol. 7, 500 https://doi. org/10.1038/msb.2011.34

48 Stelling, J., Klamt, S., Bettenbrock, K., Schuster, S. and Gilles, E.D. (2002) Metabolic network structure determines key aspects of functionality and regulation. Nature 420, 190-193 https://doi.org/10.1038/nature01166

49 de Figueiredo, L.F., Podhorski, A., Rubio, A., Kaleta, C., Beasley, J.E., Schuster, S. et al. (2009) Computing the shortest elementary flux modes in genome-scale metabolic networks. Bioinformatics 25, 3158-3165 https://doi.org/10.1093/bioinformatics/btp564

50 Holzhütter, H.-G. (2004) The principle of flux minimization and its application to estimate stationary fluxes in metabolic networks. Eur. J. Biochem. 271 2905-2922 https://doi.org/10.1111/j.1432-1033.2004.04213.x

51 Hoffmann, S., Hoppe, A. and Holzhütter, H.-G. (2006) Composition of metabolic flux distributions by functionally interpretable minimal flux modes (MinModes). Genome Inform. 17, 195-207 PMID:17503369

52 Poolman, M.G., Venkatesh, K.V., Pidcock, M.K. and Fell, D.A. (2004) A method for the determination of flux in elementary modes, and its application to Lactobacillus rhamnosus. Biotechnol. Bioeng. 88, 601-612 https://doi.org/10.1002/bit.20273

53 Goelzer, A. and Fromion, V. (2011) Bacterial growth rate reflects a bottleneck in resource allocation. Biochim. Biophys. Acta, Gen. Subj. 1810, 978-988 https://doi.org/10.1016/j.bbagen.2011.05.014

54 Goelzer, A., Fromion, V. and Scorletti, G. (2011) Cell design in bacteria as a convex optimization problem. Automatica 47, 1210-1218 https://doi.org/ 10.1016/j.automatica.2011.02.038

55 Goelzer, A. and Fromion, V. (2017) Resource allocation in living organisms. Biochem. Soc. Trans. 45, 945-952 https://doi.org/10.1042/BST20160436

56 Tilman, D. (1982) Resource Competition and Community Structure. Princeton University Press, Princeton, p. 296

57 Kitano, H. (2010) Violations of robustness trade-offs. Mol. Syst. Biol. 6, 384 https://doi.org/10.1038/msb.2010.40

58 Alexeeva, S., de Kort, B., Sawers, G., Hellingwerf, K.J. and de Mattos, M.J.T. (2000) Effects of limited aeration and of the ArcAB system on intermediary pyruvate catabolism in Escherichia coli. J. Bacteriol. 182, 4934-4940 https://doi.org/10.1128/JB.182.17.4934-4940.2000 
59 Varma, A. and Palsson, B.0. (1994) Stoichiometric flux balance models quantitatively predict growth and metabolic by-product secretion in wild-type Escherichia coli W3110. Appl. Environ. Microb. 60, 3724-3731 PMCID:201879

60 Carlson, R. and Srienc, F. (2004) Fundamental Escherichia coli biochemical pathways for biomass and energy production: identification of reactions. Biotechnol. Bioeng. 85, 1-19 https://doi.org/10.1002/bit.10812

61 Hunt, K.A., Jennings, R.D., Inskeep, W.P. and Carlson, R.P. (2016) Stoichiometric modelling of assimilatory and dissimilatory biomass utilisation in a microbial community. Environ. Microbiol. 18, 4946-4960 https://doi.org/10.1111/1462-2920.13444

62 Kornberg, H.L. (1966) The role and control of the glyoxylate cycle in Escherichia coli. Biochem. J. 99, 1-11 https://doi.org/10.1042/bj0990001

63 Fischer, E. and Sauer, U. (2003) A novel metabolic cycle catalyzes glucose oxidation and anaplerosis in hungry Escherichia coli. J. Biol. Chem. 278 46446-46451 https://doi.org/10.1074/jbc.M307968200

64 Schuetz, R., Kuepfer, L. and Sauer, U. (2007) Systematic evaluation of objective functions for predicting intracellular fluxes in Escherichia coli. Mol. Syst. Biol. 3, 119 https://doi.org/10.1038/msb4100162

65 Böck, A. and Sawers, G. (1996) Fermentation. In Escherichia Coli and Salmonella: Cellular and Molecular Biology (Neidhardt, F.C., Curtiss, R.I., Ingrahm, J.L., Lin, E.C.C., Low, K.B., Magasanik, B. et al., eds), vol. 1, 2nd edn. ASM Press, Washington, DC

66 Knappe, J. and Sawers, G. (1990) A radical-chemical route to acetyl-CoA: the anaerobically induced pyruvate formate-lyase system of Escherichia coli. FEMS Microbiol. Rev. 75, 383-398 https://doi.org/10.1016/S0168-6445(05)80006-3

67 Zhu, J., Shalel-Levanon, S., Bennett, G. and San, K.-Y. (2007) The YfiD protein contributes to the pyruvate formate-lyase flux in an Escherichia coli arcA mutant strain. Biotechnol. Bioeng. 97, 138-143 https://doi.org/10.1002/bit.21219

68 Kinnersley, M.A., Holben, W.E. and Rosenzweig, F. (2009) E Unibus Plurum: genomic analysis of an experimentally evolved polymorphism in Escherichia coli. PLoS Genet. 5, e1000713 https://doi.org/10.1371/journal.pgen.1000713

69 Wagner, A.F.V., Schultz, S., Bomke, J., Pils, T., Lehmann, W.D. and Knappe, J. (2001) Yfid of Escherichia coli and Y06l of bacteriophage T4 as autonomous glycyl radical cofactors reconstituting the catalytic center of oxygen-fragmented pyruvate formate-lyase. Biochem. Biophys. Res. Commun. 285, 456-462 https://doi.org/10.1006/bbrc.2001.5186

70 Flamholz, A., Noor, E., Bar-Even, A., Liebermeister, W. and Milo, R. (2013) Glycolytic strategy as a tradeoff between energy yield and protein cost. Proc. Natl Acad. Sci. U.S.A. 110, 10039-10044 https://doi.org/10.1073/pnas.1215283110

71 Carlson, R.P. and Taffs, R.L. (2010) Molecular-level tradeoffs and metabolic adaptation to simultaneous stressors. Curr. Opin. Biotechnol. 21, 670-676 https://doi.org/10.1016/j.copbio.2010.05.011

72 Murray, E.L. and Conway, T. (2005) Multiple regulators control expression of the Entner-Doudoroff aldolase (Eda) of Escherichia coli. J. Bacteriol. 187, 991-1000 https://doi.org/10.1128/JB.187.3.991-1000.2005

73 Fendt, S.-M., Buescher, J.M., Rudroff, F., Picotti, P., Zamboni, N. and Sauer, U. (2010) Tradeoff between enzyme and metabolite efficiency maintains metabolic homeostasis upon perturbations in enzyme capacity. Mol. Syst. Biol. 6, 356 https://doi.org/10.1038/msb.2010.11

74 Goel, A., Eckhardt, T.H., Puri, P., de Jong, A., Branco Dos Santos, F., Giera, M. et al. (2015) Protein costs do not explain evolution of metabolic strategies and regulation of ribosomal content: does protein investment explain an anaerobic bacterial Crabtree effect? Mol. Microbiol. 97, 77-92 https://doi.org/10.1111/mmi.13012

75 Hackett, S.R., Zanotelli, V.R.T., Xu, W., Goya, J., Park, J.O., Perlman, D.H. et al. (2016) Systems-level analysis of mechanisms regulating yeast metabolic flux. Science $\mathbf{3 5 4}$, aaf2786 https://doi.org/10.1126/science.aaf2786

76 Cornishbowden, A., Hofmeyr, J.H.S. and Cardenas, M.L. (1995) Strategies for manipulating metabolic fluxes in biotechnology. Bioorg. Chem. 23, 439-449 https://doi.org/10.1006/bio0.1995.1030

77 Heinrich, R. and Rapoport, T.A. (1974) A linear steady-state treatment of enzymatic chains. critique of the crossover theorem and a general procedure to identify interaction sites with an effector. Eur. J. Biochem. 42, 97-105 https://doi.org/10.1111/j.1432-1033.1974.tb03319.x

78 Kacser, H., Burns, J.A., Kacser, H. and Fell, D.A. (1995) The control of flux. Biochem. Soc. Trans. 23, 341-366 https://doi.org/10.1042/bst0230341

79 Schaaff, I., Heinisch, J. and Zimmermann, F.K. (1989) Overproduction of glycolytic enzymes in yeast. Yeast 5, 285-290 https://doi.org/10.1002/yea. 320050408

80 Hoffmann, S. and Holzhütter, H.-G. (2009) Uncovering metabolic objectives pursued by changes of enzyme levels. Ann. N. Y. Acad. Sci. 1158, 57-70 https://doi.org/10.1111/j.1749-6632.2008.03753.x

81 Fell, D.A. (1998) Increasing the flux in metabolic pathways: a metabolic control analysis perspective. Biotechnol. Bioeng. 58, 121-124 https://doi.org/ 10.1002/(SICI)1097-0290(19980420)58:2/3<121::AID-BIT2>3.0.C0;2-N

82 Bernstein, H. and Carlson, R.P. (2012) Microbial consortia engineering for cellular factories: in vitro to in silico. Comput. Struct. Biotechnol. J. 3 e201210017 https://doi.org/10.5936/csbj.201210017

83 Pande, S., Merker, H., Bohl, K., Reichelt, M., Schuster, S., de Figueiredo, L.F. et al. (2014) Fitness and stability of obligate cross-feeding interactions that emerge upon gene loss in bacteria. ISME J. 8, 953-962 https://doi.org/10.1038/ismej.2013.211

84 Mee, M.T., Collins, J.J., Church, G.M. and Wang, H.H. (2014) Syntrophic exchange in synthetic microbial communities. Proc. Natl Acad. Sci. U.S.A. 111, E2149-E2156 https://doi.org/10.1073/pnas.1405641111

85 Wintermute, E.H. and Silver, P.A. (2010) Emergent cooperation in microbial metabolism. Mol. Syst. Biol. 6, 407 https://doi.org/10.1038/msb.2010.66

86 Shou, W., Ram, S. and Vilar, J.M.G. (2007) Synthetic cooperation in engineered yeast populations. Proc. Natl Acad. Sci. U.S.A. 104, 1877-1882 https://doi.org/10.1073/pnas.0610575104

87 Bernstein, H.C., Paulson, S.D. and Carlson, R.P. (2012) Synthetic Escherichia coli consortia engineered for syntrophy demonstrate enhanced biomass productivity. J. Biotechnol. 157, 159-166 https://doi.org/10.1016/j.jbiotec.2011.10.001

88 Hillesland, K.L. and Stahl, D.A. (2010) Rapid evolution of stability and productivity at the origin of a microbial mutualism. Proc. Natl Acad. Sci. U.S.A. 107, 2124-2129 https://doi.org/10.1073/pnas.0908456107

89 LaSarre, B., McCully, A.L., Lennon, J.T. and McKinlay, J.B. (2017) Microbial mutualism dynamics governed by dose-dependent toxicity of cross-fed nutrients. ISME J. 11, 337-348 https://doi.org/10.1038/ismej.2016.141

90 Harcombe, W.R., Riehl, W.J., Dukovski, I., Granger, B.R., Betts, A., Lang, A.H. et al. (2014) Metabolic resource allocation in individual microbes determines ecosystem interactions and spatial dynamics. Cell Rep. 7, 1104-1115 https://doi.org/10.1016/j.celrep.2014.03.070 
91 Brileya, K.A., Camilleri, L.B., Zane, G.M., Wall, J.D. and Fields, M.W. (2014) Biofilm growth mode promotes maximum carrying capacity and community stability during product inhibition syntrophy. Front. Microbiol. 5, 693 https://doi.org/10.3389/fmicb.2014.00693

92 de Mazancourt, C. and Schwartz, M.W. (2010) A resource ratio theory of cooperation. Ecol. Lett. 13, 349-359 https://doi.org/10.1111/j.1461-0248. 2009.01431.x

93 Kinnersley, M., Wenger, J., Kroll, E., Adams, J., Sherlock, G. and Rosenzweig, F. (2014) Ex uno plures: clonal reinforcement drives evolution of a simple microbial community. PLoS Genet. 10, e1004430 https://doi.org/10.1371/journal.pgen.1004430

94 Bennett, B.D., Kimball, E.H., Gao, M., Osterhout, R., Van Dien, S.J. and Rabinowitz, J.D. (2009) Absolute metabolite concentrations and implied enzyme active site occupancy in Escherichia coli. Nat. Chem. Biol. 5, 593-599 https://doi.org/10.1038/nchembio.186

95 Noor, E., Flamholz, A., Bar-Even, A., Davidi, D., Milo, R. and Liebermeister, W. (2016) The protein cost of metabolic fluxes: prediction from enzymatic rate laws and cost minimization. PLoS Comput. Biol. 12, e1005167 https://doi.org/10.1371/journal.pcbi.1005167

96 Pfeiffer, T. and Bonhoeffer, S. (2004) Evolution of cross-feeding in microbial populations. Am. Nat. 163, E126-E135 https://doi.org/10.1086/383593

97 Kolter, R. (2005) Surfacing views of biofilm biology. Trends Microbiol. 13, 1-2 https://doi.org/10.1016/j.tim.2004.11.003

98 Stewart, P.S. and Franklin, M.J. (2008) Physiological heterogeneity in biofilms. Nat. Rev. Microbiol. 6, 199-210 https://doi.org/10.1038/nrmicro1838

99 Chacón, J., Moebius, W. and Harcombe, W. (2017) https://doi.org/10.1101/111153

100 Nadell, C.D., Drescher, K. and Foster, K.R. (2016) Spatial structure, cooperation and competition in biofilms. Nat. Rev. Microbiol. 14, 589-600 https://doi.org/10.1038/nrmicro.2016.84

101 Momeni, B., Brileya, K.A., Fields, M.W. and Shou, W. (2013) Strong inter-population cooperation leads to partner intermixing in microbial communities. elife 2, e00230 https://doi.org/10.7554/eLife.00230

102 Henson, M.A. (2015) Genome-scale modelling of microbial metabolism with temporal and spatial resolution. Biochem. Soc. Trans. 43, 1164-1171 https://doi.org/10.1042/BST20150146

103 Harcombe, W.R., Betts, A., Shapiro, J.W. and Marx, C.J. (2016) Adding biotic complexity alters the metabolic benefits of mutualism. Evolution 70, 1871-1881 https://doi.org/10.1111/evo.12973

104 Cole, J.A., Kohler, L., Hedhli, J. and Luthey-Schulten, Z. (2015) Spatially-resolved metabolic cooperativity within dense bacterial colonies. BMC Syst. Biol. 9, 395 https://doi.org/10.1186/s12918-015-0155-1

105 Phalak, P., Chen, J., Carlson, R.P. and Henson, M.A. (2016) Metabolic modeling of a chronic wound biofilm consortium predicts spatial partitioning of bacterial species. BMC Syst. Biol. 10, 497 https://doi.org/10.1186/s12918-016-0334-8

106 Jayasinghe, N., Franks, A., Nevin, K.P. and Mahadevan, R. (2014) Metabolic modeling of spatial heterogeneity of biofilms in microbial fuel cells reveals substrate limitations in electrical current generation. Biotechnol. J. 9, 1350-1361 https://doi.org/10.1002/biot.201400068

107 Henson, M. and Phalak, P. (2017) Byproduct cross feeding and community stability in an in silico biofilm model of the gut microbiome. Processes $\mathbf{5}, 13$ https://doi.org/10.3390/pr5010013

108 Hellweger, F.L., Clegg, R.J., Clark, J.R., Plugge, C.M. and Kreft, J.-U. (2016) Advancing microbial sciences by individual-based modelling. Nat. Rev. Microbiol. 14, 461-471 https://doi.org/10.1038/nrmicro.2016.62

109 Schepens, D., Beck, A.E., Heys, J.J., Gedeon, T. and Carlson, R.P. (2017) The benefits of resource partitioning and division of labor in microbial consortia. In Advances in Systems and Synthetic Biology (Amar, P., Kepes, F. and Norris, V., ed.), pp. 137-148. EDP Sciences Publishing

110 Venters, M., Carlson, R.P., Gedeon, T. and Heys, J.J. (2017) Effects of spatial localization on microbial consortia growth. PLoS ONE 12, e0168592 https://doi.org/10.1371/journal.pone.0168592

111 Bauer, E., Zimmermann, J., Baldini, F., Thiele, I. and Kaleta, C. (2017) Bacarena: individual-based metabolic modeling of heterogeneous microbes in complex communities. PLoS Comput. Biol. 13, e1005544 https://doi.org/10.1371/journal.pcbi.1005544 